\title{
Direct and Free Direct Forms of Representation IN THE Discourse OF NeWSPAPER REPORTS: Less Frequent Phenomena
}

\begin{abstract}
This paper comments on selected aspects of free direct and direct forms of representation occurring in a corpus of British newspaper reports and describes them from a number of perspectives. A few comments are made on the corpus studied, speech, writing and thought distinction and the frequency of occurrence of the individual forms on each scale. Since the use of reported language in newspaper reports has been studied thoroughly from a number of angles, the present paper turns attention to phenomena that occur less frequently but nevertheless are worth examining. The aspects focused on are embedded direct and free direct reports, direct thought reports and hypothetical (free) direct reports. These phenomena are interpreted in terms of the overall function of reported language in newspaper reports and the connection between them is discussed.
\end{abstract}

Key words

Newspaper reports; embedded direct and free direct forms of representation; hypothetical free direct and direct reports; direct reported thought

\section{Introduction}

The paper addresses the question of direct and free direct reported speech, writing and thought in the discourse of newspaper reports. Reported language (and thought) in general has become an integral part of newspaper reporting; newspaper reporters rely on the language of others by means of which different perspectives are brought into the text, resulting in a mixture of voices. The notion of perspective or point of view (see e.g. Fludernik 1993: 319-332; Ehrlich 1990) from which an 
event is narrated is central to all forms of representation. Reported language can be thought of as a scale where the most non-direct forms reflect primarily the point of view of the reporting speaker, and those purely direct reflect the perspective of the reported speaker (e.g. Semino and Short 2004; Semino et al. 1997). Even though pure direct and free direct forms are said to be deictically and speech-functionally autonomous (e.g. Vandelanotte 2009; Sternberg 1982), the fact that we are concerned with the phenomenon of reported language, i.e. a piece of language that has been taken out of its original context and placed in a new context, forces us to view it in terms of the function it has been employed to play in the latter (see e.g. Tannen 2007; Ikeo 2009; Sternberg 1982). ${ }^{1}$ A newspaper report is thus essentially dialogic: (free) direct forms of representation bring into a text the voice of others, exhibiting various speech styles; both aspects interact, or enter into a dialogue, with the voice and style of the news reporter (Bakhtin 1986).

The present paper addresses less frequently occurring phenomena, namely direct reported thought, hypothetical and embedded direct reported discourse and tries to find a relation between them. These aspects are marginal in the discourse of newspaper reports and do not represent the prototypical uses of (free) direct reported language. Still, the paper interprets them in connection with the concept of deictic centre, point of view or perspective and the commonly cited functions of reported language in newspaper reports, such as persuasiveness, newsworthiness, evidentiality, personalization, objectivity, reliability and credibility (Waugh 1995; Caldas-Coulthard 1994; van Dijk 1988). In the beginning it is convenient, however, to define the concept of (free) direct reported discourse (F)DD, comment on its formal properties and offer a few comments on the data analyzed.

\section{Direct and free direct reported discourse: conceptual delimitation}

The aim of this chapter is to delimit conceptually free direct and direct reported discourse. As will be argued below, free direct and direct reported forms are identical in terms of their deictic properties. Simultaneously, however, they differ in the presence (DD) or absence (FDD) of quotation marks and/or a reporting clause occurring within the same sentence (Leech and Short 1981: 322). Example 1 below illustrates direct speech (DS) and free direct speech (FDS) without a reporting clause. Now attention will be paid to the aspects of DD and FDD which bring the two categories together rather than apart. Consequently, the description will apply to both forms.

Direct and free direct reported discourse, as any form of reported language and thought, can be viewed from a number of not unrelated perspectives. The traditional view defines forms of reported discourse in terms of verbatim representation of or faithfulness to the original: (free) direct reported forms are such forms which represent the reported event in a manner faithful to form, content and speech act value (see e.g. Short et al. 2002). However, as argued by many, faithfulness is not a necessary concept in the delimitation of (F)DD (see e.g. 
Sternberg 1982; Tannen 2007; Ikeo 2009; Vandelanotte 2009) and can only potentially result from the deictic properties of the reported element. As pointed out by Sternberg (1982: 110), (F)DD is a "double-centered deictic structure" where "the inset [reported clause] takes its orientation from the speech event ... whose coordinates diverge in principle from those of the ... frame [reporting clause]". Thus (F)DD as a whole is a deictically dual structure with a clear separation of the deictic centre of the reporting and reported element (Sternberg 1982: 110). This makes the reported element deictically independent of the reporting clause and enables the reporter to "fully re-enact" (Vandelanotte 2009: 188, 240) or "demonstrate" (Clark and Gerrig 1990), i.e. to act out anew, the speech function and other interpersonal meanings of the reported event. Equally importantly, the reenactment (or demonstration) is realized by language forms that occur in primary, non-reported discourse, such as interrogative and imperative structure, vocatives, interjections, discourse markers, incomplete chunks etc. (Banfield 1973: 6-10, 27; Vandelanotte 2009: 41-50; Sternberg 1982: 108-112). The full re-enactment of the speech event and transfer of the reported deictic centre into the narrative context brings with itself the sense of immediacy, vividness, drama or personalization since it is primarily the reported speaker whose perspective is represented (re-enacted). Whether a (free) direct report conforms at the same time to the three faithfulness claims mentioned above may not be relevant. In example 1, Condoleezza Rice demonstrates in the form of direct speech (DS) and free direct speech (FDS) her conversation with Aretha Franklin, an American singer. Example 2, DS, is a conversation between father and daughter before a parasailing accident. Notice also that there occur instances of DS (in italics) within (F)DS.

(1) $<\mathrm{DS}>$ "We [Ms Rice and Ms Franklin] were just talking and chatting, Ms Rice recalled. $<$ FDS $>$ She [Ms Franklin] said $\langle D S>$ ' You [Ms Rice] play, don't you?' And I [Ms Rice] said, $<D S>$ 'Yes'. And she said we should do something together." (The Independent, July 29, 2010)

(2) She said: $<\mathrm{DS}>$ "I asked what would happen if you hit the water from that height and he said, $\langle D S>$ 'You wouldn't survive it, anyway.' I said $<D S>$ 'Thanks for reassuring me, Dad!' I never imagined it would happen."

(The Independent, July 29, 2010)

The above examples are rich in expressions evocative of the reported situation (underlined) and not likely to appear in non-direct reported discourse: first and second person pronouns, referring to the reported speaker and his addressee respectively (you in 1, I and $m e$ in 1 and 2), ${ }^{2}$ a question tag and non-clausal structure (Yes) in 1 or a vocative ( $\mathrm{Dad}$ in 2). All these forms are expressive of the reported speaker's deictic centre and the whole reported situation. By being re-enacted rather than described, they make the conversation 'come alive' on page, render it more authentic and give the reader an opportunity to witness or experience it more directly. It cannot pass unnoticed that the italicised direct reports form short 
dialogues reminiscent of those found e.g. in fiction or spoken narrative (see e.g. Tannen 1986, 2007). Also, the question of faithfulness may not be at issue; such dialogic direct reports are viewed as, rather than reporting acts, constructed narrative acts (Tannen 2007: 125).

FDD and DD are identical in terms of the retention of the deictic centre, the potential to re-enact fully the reported event (Vandelanotte 2009: 41-50) as well as the three faithfulness claims (Short 1988: 70-71). Consequently, sometimes FDD is not considered a separate category but only a pragmatic variant of DD (see e.g. Semino and Short 2004: 88; Short 1988: 70-71; Vandelanotte 2009: 3-4). As noted above, the present approach follows Leech and Short (1981) and retains the distinction between FDD and DD. In the main body of newspaper reports FDD always follows a speech/writing or thought report or at least a narrator's passage with a clear reference to the reported speaker within or across paragraph boundary; as a result, the source of attribution can be identified without doubt. FDD seems to be employed largely in order to avoid repetition and/or save space (e.g. Semino and Short 2004: 194-197; Vandelanotte 2009: 3-4)³.

\section{Data}

The following paragraphs will be devoted to the description of the corpus and the frequency of occurrence of (F)DD. The corpus comprises newspaper reports excerpted from four British broadsheet newspapers, namely The Daily Telegraph, The Guardian, The Independent and The Times. The reports were excerpted from two issues per each type of paper, July and October 2010. The corpus is limited only to newspaper reports, excluding other kinds of writing found in debate and opinion sections, letters etc. Table 1 below describes the corpus in terms of the number of unambiguous (F)DD (892), the total number of words and the number of words reported in the form of (F)DD. The number of words quoted directly in (F)DD constitutes $19 \%$ of all words in the corpus, i.e. almost one fifth. This is a considerable number and testifies to the significance of (F)DD in newspaper reporting. ${ }^{4}$

Table 1. The corpus

\begin{tabular}{|c|c|c|c|}
\hline Total No of words & No of words in (F)DD & Total No of (F)DD & $\begin{array}{c}\text { No of (F)DD per } \\
\mathbf{1 0 0 0} \text { words }\end{array}$ \\
\hline $105905 / 100 \%$ & $20142 / 19 \%$ & 892 & 8.4 \\
\hline
\end{tabular}

Table 2 below summarizes the results of the analysis from two perspectives: the speech - writing - thought distinction and the free direct vs. direct form distinction. Since pragmatically FDD can be considered a mere variant of DD, attention will be paid mainly to the former aspect. 
Table 2. DD and FDD in the corpus

\begin{tabular}{|l|r|r|c|}
\hline \multicolumn{4}{|c|}{ DIRECT FORMS : excluding ambiguities } \\
\hline SCALE & FDD & \multicolumn{1}{c|}{ DD } & TOTAL \\
\hline SPEECH & 247 & 543 & 790 \\
\hline WRITING & 23 & 70 & 93 \\
\hline THOUGHT & 0 & 9 & 9 \\
\hline TOTAL & 270 & 622 & 892 \\
\hline
\end{tabular}

As follows from Table 2, speech reports predominate over writing and thought reports. The difference in frequency of occurrence between speech (790) and writing reports (93) results partially from the approach adopted in the analysis. A report was viewed as a speech report unless there was a clear indication in the text that a writing event was being reported. The same strategy was followed by Semino and Short (2004). The low frequency of occurrence of direct thought (DT, 9) is ascribable to its nature. Thought is different from both speech and writing in that it is a private phenomenon not amenable to direct observation and may not be verbalized, hence theoretically impossible to report in direct form (Leech and Short 1981: 344-345). Moreover, the newspaper reporter cannot assume a role of the so-called omniscient narrator who has access to the mind of the individual whose thoughts or beliefs are reported. Consequently, the reporter tends to resort to a non-direct and hence less "forced and artificial" (Semino and Short 2004: 118) form of thought report. If a DT occurs at all, it is "embedded" in, i.e. contained within, another speech or writing report (Semino and Short 2004: 33-35), often as a self-quote; or a DT is an (embedded) hypothetical form, e.g. a report that is presented as pertaining to other than the actual, past or real world (Sternberg 1982; Tannen 2007; Ryan 1991; Semino et al. 1999).

Though the phenomena of embedding, hypothetical (F)DD and DT are examined in separate chapters, due to a close relationship between them it is impossible to treat them in isolation and reference will be made to them across chapters. Since embedding is an aspect co-occurring with both DT and hypothetical (F) $\mathrm{DD}$, it will be dealt with first.

\section{Embedding}

As mentioned above, the concept of embedding describes an occurrence of one form of representation within the confines of another (Semino and Short 2004: $33-35,171-182)$. It results in a recursive pattern similar to $A$ said that $B$ said that $C$ said that ... and since in its effect such reported discourse is doubly-, triply- or multi-reflexive, it also contributes to the multiplicity of voices in the text (see examples 1 and 2 above).

As for function, it is mostly (F)DD, especially speech, that serves as a host to mainly non-direct reported forms. The reported element of (F)DD is deictically independent, separated from the reporting clause (if present) and the whole struc- 
ture is syntactically looser than in non-direct forms. Nevertheless, in the data analysed there have occurred a few cases where the opposite relationship obtains, i.e. (F)DD appears embedded in other direct or non-direct form. Though in order to obtain a complete picture of how embedding works, both host categories as well as embedded ones need to be studied together, attention will be paid here only to embedded (E) free direct and direct forms. The data are summarized below. The numbers accompanying the abbreviation $\mathrm{E}$ indicate the level of embedding: E0 refers to a non-embedded (F)DD, E1 and E2 indicate levels 1 and 2 respectively. E1 abbreviates an instance of (F)DD embedded in a non-embedded form of representation (E0). E2 indicates the highest level of embedding found in the texts analysed and hence more complex structures, in which an embedded form of report at E1 contains within itself an instance of (F)DD at E2.

Table 3. Embedded and non-embedded (F)DD

\begin{tabular}{|c|c|c|c|c|c|c|c|c|c|}
\hline & \multicolumn{4}{|c|}{ DD } & \multicolumn{4}{|c|}{ FDD } & \multirow[t]{2}{*}{ TOTAI } \\
\hline & E0 & E1 & E2 & E1-E2 & E0 & E1 & E2 & E1-E2 & \\
\hline SPEECH & 519 & 20 & 4 & 24 & 240 & 7 & 0 & 7 & 790 \\
\hline WRITING & 67 & 3 & 0 & 3 & 23 & 0 & 0 & 0 & 93 \\
\hline THOUGHT & 0 & 8 & 1 & 9 & 0 & 0 & 0 & 0 & 9 \\
\hline \multirow[t]{2}{*}{ TOTAL } & 586 & 31 & 5 & 36 & 263 & 7 & 0 & 7 & 892 \\
\hline & 586 & & & 36 & 263 & & & 7 & 892 \\
\hline
\end{tabular}

As Table 3 shows, free direct (263) and direct (586) forms appear mostly nonembedded (E0); this corresponds with the fact noted above, namely that (F)DD normally functions as a host. Though instances of embedded (F)DD are not numerous, there appear tendencies both in terms of speech, writing and thought distinction and in terms of the FDD vs. DD distinction. As for the former perspective, embedded FDS (7 cases) and DS (24 cases) appear at both levels of embedding (E1 and E2) and outnumber (free) direct writing, (F)DW, and (free) direct thought, (F)DT. This is in correspondence with the overall predominance of speech representation over writing and thought. However, there is a twist in the writing vs. thought ratio: non-embedded (F)DW (90) outnumbers non-embedded (F)DT (0); instances of DT, however, appear at E1 (8 cases) and E2 (1 case) and outnumber embedded DW (3 cases), appearing only at E1. Though the overall frequency of embedded DT is in no way significant, its appearance at E1 and E2 in contrast to its total absence at E0 goes hand in hand with the nature of reported thought noted above. In embedded DT the responsibility lies with the author of the host (F)DD, not the newspaper reporter, and even in these cases embedded DT is often a self-quote (e.g. example 10) or an instance of hypothetical DT (e.g. example 11). As will be shown below, such forms play different roles than typically ascribed to (non-embedded) (F)DS or (F)DW. 
As far as the free direct vs. direct discourse distinction is concerned, embedded DD ( 36 cases) is more common than FDD ( 7 cases), presumably because in the presence of different voices the reporting clause indicates clearly the source of the embedded direct report. As noted above, non-embedded instances of FDD always follow a clearly identified source within or across paragraph boundary; example 3 illustrates a similar strategy with the source (we) identified outside the embedded (E1) FDS (in italics).

(3) Rogan Taylor, ... said: $<\mathrm{e} 0>$ "We've got the ultimate fit and proper person test for any incoming owner. $<$ el $>$ Do you want a partnership with equity providing fans? If not, then what are you doing here? (The Guardian, July 29, 2010)

The examples of embedded direct forms with a reporting clause but without quotation marks (see e.g. example 6 below) were classified in accordance with the coding conventions, i.e. as FDD, though the presence or absence of quotation marks seems rather an arbitrary decision of the reporter. Nevertheless, since in these cases the presence or absence of quotation marks does not have any consequences for the function of embedded forms, it can be considered of minor significance. Also, note that the embedded FDD in example 3 is a type of hypothetical report; the questions are not directed at the current addressee but at a hypothetical one - any incoming owner, to whom the second person pronoun you refers. It (re-)enacts a possible scenario demonstrating a hypothetical conversation by means of which a description of a (dis)preferred incoming owner is given. Such hypothetical forms are typical of spoken language but embedding enables the news reporter to incorporate them into a completely different type of text. More will be said on hypothetical (F)DD below.

The last aspect that is worth mentioning concerns the level of embedding. The level of embedding is in inverse proportion to frequency: whereas there are 849 instances of (F)DD at E0 (586 and 263 of DD and FDD respectively), there are 38 instances of (F)DD at E1 (31 and 7 of DD and FDD respectively), and only 5 instances at E2, all DD. A higher level of embedding results in a complexity of the whole reporting structure in terms of syntax, deictic orientation and multiplicity of voices present. This is especially true if the host categories are non-direct forms, which means the whole structure is syntactically more demanding. (F)DD at E1 was already illustrated by examples 1, 2 and 3 above; example 4 illustrates the use of DS at E2, with the levels of embedding indicated in brackets.

(4) Over supper in his kitchen with his wife Samantha four days after the 6 May election resulted in a hung parliament, $<\mathrm{e} 0>\mathrm{Mr}$ Cameron said $<e l>h e$ recalls saying: <e2> "It's not going to happen. I'm going to be leader of the Opposition. $\leq e 3>$ I'm depressed that it hasn't worked out as we wanted it. I'm going to be in opposition for another couple more years."

(The Independent, July 29, 2010) 
In example 4, the instance of DS (E2, in bold) is embedded in indirect thought (E1, in italics), itself embedded in indirect speech (E0). Due to the level of embedding and a mixture of thought and speech reports the whole structure is quite complex, with speech (E0) reporting thought (E1) via which DS is communicated (E2). It will have been noticed that the embedded DS at E2 functions simultaneously as a host category and embeds an instance of internal narration (Semino and Short 2004: 45-47), a minimal form of representation on thought scale (E3, underlined), commenting on David Cameron's emotional state (depressed). This increases the level of complexity even further.

(5) $\mathrm{Mr}$ Gove backed concerns from the actress Emma Thompson $<\mathrm{e} 0>$ who said $<e 1>$ she was appalled to hear children saying $<\boldsymbol{e} 1>$ "innit" and $<\boldsymbol{e} 1>$ "do I look bovvered".

(The Daily Telegraph, October 6, 2010)

Example 5 is also considerably complex: not only is it a mixture of thought and speech scales, it also contains two different voices (Emma Thompson and children). The two coordinated DSs (E1, in bold italics) and internal narration (E1, in italics), expressing Emma Thompson's emotional reaction (appalled), appear embedded within an instance of indirect speech (E0). ${ }^{5}$ In addition, these DSs are noteworthy since the unconventional spelling draws attention to the spoken features of the supposed original utterances, making the form more salient than the propositional content. In such cases, (F)DD is an obvious choice since it enables the reporter to foreground formal aspects and at the same time distance himself/ herself from a form inappropriate in the reporting context.

Let us now consider the following example:

(6) a. $<\mathrm{e} 0>$ "I know how anxious people are. $<e 1>$ Yes, they say, of course we need to cut spending. But do we have to cut now, and by this much? Is there another way?

b. $<\mathrm{e} 0>$ "I wish there was another way. I wish there was an easier way. But I tell you: there is no other responsible way. Back in May we inherited public finances that can only be described as catastrophic."

(The Guardian, October 7, 2010)

In example $6 \mathrm{Mr}$ Cameron, quoted by means of FDS (E0, in bold) in a. and b., argues for the need to make spending cuts. In a., he brings into the report the voice of 'the ordinary citizen' (FDS, E1 in italics) in order to show empathy and understanding; the embedded FDS facilitates this impression since, being direct in form, it reflects primarily the perspective of the reported speaker at E1, i.e. the general public. The fact that he uses FDS with a plural subject (they) goes against the concept of faithfulness and the embedded FDS needs to be understood as a general or summarizing statement of what any member of the public might say. Even though Mr Cameron does not assume the role of the principal - an entity whose stance is being expressed, he is both the author and animator (Goffman 
1981: 144). Apart from showing understanding and empathy, Mr Cameron uses the embedded FDS as a preparatory move to counter-argue and put forward his argument: in b. he exploits the content and partially the form (the noun way) of the embedded FDS to air his opinion and argue for the need to cut spending. $\mathrm{He}$ leads a kind of dialogue with the public, and consequently also with the reader of the report. The embedded FDS is a result of an "active, creative" act rather than a genuine reporting act (Tannen 2007: 111), constructed for the purpose of showing awareness of the public's point of view and its subsequent refusal. Such (F) DDs do not appear non-embedded in newspaper reports due to their constructed nature and a very general source of attribution, which may not be considered quoteworthy for the newspaper reporter unless subordinated to the function of the host; the excerpt as a whole adds evaluative and argumentative dimension to the report.

The above examples have shown (F)DD embedded at different levels in both direct and non-direct forms of representation. Not unexceptionally embedded direct forms are instances of DT and hypothetical (F)DD. These issues will be treated in the following paragraphs and more examples will be provided which illustrate DT and hypothetical forms combined with embedding.

\section{Hypothetical direct and free direct forms of representation}

As shown above (example 3), it is possible to find instances of reported language that clearly are not reports per se, i.e. they do not present the language of others as actual, uttered prior to the reporting situation. Hypothetical reported language and thought present reported events as something non-actual, e.g. "future, possible, imaginary or counter-factual" (Semino et al. 1999: 308; see also Sternberg 1982; Tannen 2007; Ryan 1991). Consequently, a news report may be a mixture of the actual world and some possible world(s), which complement or interact with each other. Naturally, hypothetical (F)DD is not the only source of hypothetical discourse in newspaper reports but it enables the reporter to bring in the nonactual into the story without assuming responsibility for the 'reported' content.

In newspaper reports hypothetical (F)DD appears less readily than hypothetical non-direct reported forms (for more details see Semino and Short 2004: 159-171). As Table 4 shows, there appeared no more than 28 examples in the whole corpus.

Table 4. Hypothetical (F)DD

\begin{tabular}{|l|c|c|c|c|c|c|c|}
\hline & \multicolumn{2}{|c|}{ E0 } & \multicolumn{2}{c|}{ E1 } & \multicolumn{2}{c|}{ E2 } & \\
\hline & FDD & DD & FDD & DD & FDD & DD & TOTAL \\
\hline SPEECH & 8 & 11 & 4 & 1 & 0 & 1 & 25 \\
\hline WRITING & 0 & 0 & 0 & 0 & 0 & 0 & 0 \\
\hline THOUGHT & 0 & 0 & 0 & 2 & 0 & 1 & 3 \\
\hline TOTAL & 8 & 11 & 4 & 3 & 0 & 2 & 28 \\
\hline & \multicolumn{3}{|c|}{19} & \multicolumn{7}{|c|}{7} & \multicolumn{2}{|c|}{2} & \\
\hline
\end{tabular}


As expected, hypothetical speech ( 25 cases) prevails both over writing (0) and thought ( 3 cases). This is connected to the overall frequency of each type of report and the uses hypothetical reports are put to in newspaper reporting. Only about one third ( 9 cases) out of the 28 instances of hypothetical forms are embedded (7 instances at E1 and 2 at E2). The embedded hypothetical form in example 3 is attributed to specific individuals (we). In the following example, a part of David Cameron's address to the Conservative Party during their conference in October 2010, the embedded FDS is attributed to the society as a whole:

$<\mathrm{e} 0>$ "It's about government helping to build a nation of doers and gogetters, where people step forward not sit back, where people come together to make life better... A country, a society where $<e 1>\underline{\text { we }}$ say: $\underline{\text { I am not }}$ alone. I will play my part." ～(The Independent, October 7, 2010)

Example 7 is similar to example 6 in that the embedded FDS (in italics) is attributed to people in general, in this case including the PM, by means of the inclusive we; but it is not used to report what the public says or believes in in the actual world but what it should say or believe in in the society the PM has envisaged or considers ideal, right and desirable. In this case it is not only the FDS that is hypothetical but the whole picture of the society portrayed by the PM ( a nation of doers and go-getters, where people step forward ... better) that belongs to the realm of the possible rather than the real. Within the newspaper report as a whole it is a part of the evaluative comment, presenting the politician's values or ideals but in a manner that involves the public as well: the embedded hypothetical FDS is not attributed to him but to the whole society (we); the pronouns $I$ and $m y$ in the reported clause refer to any individual member of the society and thus reflect primarily his or her perspective and point of view. Thus the politician lets the public speak for himself. Non-embedded (F)DD is mostly attributed to elite persons, who by their association with authority and prestige can increase the value of the news story (Bell 1991: 158). On the contrary, members of the general public are less quote-worthy, unless they are involved in an event that is newsworthy in itself, e.g. as eye-witnesses (example 2). This explains why instances of (non)hypothetical (F)DD such as those exemplified by 6 and 7 above (and 11 below) are unlikely to appear non-embedded both on account of the source quoted as well as the functions they serve.

Let us now turn attention to the non-embedded hypothetical (F)DD. Though it is impossible to generalize on the basis of such low numbers, there seems to be a connection between non-embedded and embedded hypothetical (F)DD and the functions it plays in the text. All non-embedded hypothetical forms are speech forms of the type illustrated by examples 8 and 9 , referring to future and fictional speech events respectively.

(8) a. Cameron: $<\mathrm{e} 0>$ we must back doers and grafters who will get economy moving 
b. He will say: $<\mathrm{e} 0>$ "It will be the doers and the grafters, the inventors and the entrepreneurs who get this country going. Yes, it will be the wealth-creators - and no, those aren't dirty words."

(The Daily Telegraph, October 6, 2010)

Example 8b. illustrates an instance of hypothetical DS - a part of David Cameron's speech mentioned above. Its hypothetical status results from the fact that the newspaper report was published prior to the event and the DS is presented as a future act (modal will). The attribution of the non-embedded DS to a particular person uttering it at a specific future occasion makes it noticeably different from the embedded hypothetical forms in examples 7 above and 11 below, which are rather generic, typifying statements not attributed to any specific individual. The FDS in $8 \mathrm{a}$. found in the headline presents a kind of summary or gist of the speech with a degree of overlap in content and form with $8 \mathrm{~b}$. There is no indication of its hypothetical nature, revealed to the reader only in the body of the text. We can only speculate whether this kind of misrepresentation is done for the reasons of economy or in order to intentionally present the report as non-hypothetical, and hence as a part of the real rather than future world, or both.

Example 9 illustrates a rather unusual use of DS that could be also viewed as hypothetical: it is an excerpt from a drama fiction produced by Channel 4 in which Prince Harry is kidnapped by the Taliban. The fact that the reported utterance is part of the fiction world but placed in the context (both linguistic and situational) of the real world seems to move it closer to hypothetical forms of representation.

(9) Harry is shown appearing on a Taliban video saying: $<\mathrm{e} 0>$ "My name is Captain Harry Wales. I'm being fed, I'm comfortable and I'm being looked after very well. The price of my release is that coalition troops must leave Afghanistan, starting immediately. If that does not happen, I will never return home and you will never find my body."

(The Guardian, October 7, 2010)

It is clear that examples 8 and 9 are different from the discussed instances of embedded hypothetical (F)DD: they do not serve as vehicles of evaluation or comment presented through the voice of a third party; nor do they present possible arguments and counter-arguments via enacting a simulated dialogue with others. Placed in the context of a newspaper report, this other voice appears embedded in the language other than the newspaper reporter's. On the other hand, examples like 8 and 9 do not evaluate but predict what will be said in future or state what has been said in an alternative world. 


\section{Direct thought}

With its nine occurrences in the whole corpus (see Table 2 above), direct thought represents the least frequently occurring type of direct report. This is related both to the nature of thought reports as well as the type of discourse studied. As already pointed out, thought is by nature not directly observable and thus impossible to report in the strict sense. Consequently, all instances of DT are embedded in other forms of representation. In most cases DTs are either self-quotes or instances of hypothetical forms of representation. Examples 10 and 11 illustrate the two phenomena.

(10) Dannatt, commanding Nato troops in Germany at the time, told the Chilcot inquiry: $<\mathrm{e} 0>$ 'I was totally unaware. $<e 1>$ 'Where did it come from?' was my feeling at the time."

(The Guardian, July 29, 2010)

The direct thought (E1, in italics) in example 10 is embedded in a host category of DS (E0); it is a self-report, i.e. the reporter (Dannatt) is identical with the person whose thoughts are being reported and so the problem of access to the mind of the reported speaker does not arise. Moreover, whether these were the exact words that were going through his mind is not relevant and since the reader is allowed to see for himself/herself what the reported speaker thought as if on the spot, the re-enacted thought has the same dramatizing effect as e.g. DS.

Example 11 below illustrates the use of two different forms of direct thought report but differs from example 10 in a number of ways. It is more complex in terms of the level of embedding: it starts as an instance of indirect speech (E0) which embeds a case of indirect thought combined with a stretch of partially quoted direct thought (E1, in italics) which contains within itself a case of direct thought (E2, in bold).

(11) $<\mathrm{e} 0>$ Mark Field, ..., said on Radio 4's World at One that $\langle e 1>$ he feared there would be "many aspirational people who are probably on £35,004 a year or so who may not necessarily lose their benefit now but think, $<e 2>$ 'well, in a couple of promotions' time, I could be in that boat'.'

(The Daily Telegraph, October 6, 2010)

Contrary to example 10, example 11 is not an instance of self-report; the embedded DT (E2, in bold) is not attributed to the reporting speaker (Mart Field) but to others, a group of people vaguely referred to as many aspirational people, individualized in the reported clause by means of the first person pronoun. A similar strategic combination of embedded hypothetical form attributed to a general source can be found in example 7. The hypothetical interpretation of this DT is triggered by its allocation to future and its being presented merely as a possibility. In its collective reference to a group of people it also shows similarity to example 6 above. In contrast to example 6 , where the voice of the public was ultimately 
used to express disagreement, example 7 implies agreement and the embedded DT is employed in order to air one's own opinion but by means of 'wrapping it up' as the perspective or point of view of the others'. This strategy results in a merger of voices in the real and hypothetical worlds involving simultaneously identification with and distance from the ideas expressed.

\section{Conclusion}

The above paragraphs look at less common features associated with free direct and direct forms of representation in the discourse of newspaper reports, namely embedding, DT and hypothetical (F)DD. Though they must be considered marginal on account of their function and low frequency of occurrence, when they are not viewed in isolation and/or are interpreted in connection with the role of reported language in newspaper reports, clear patterns arise.

The presence of free direct and direct reported language in newspaper reporting contributes to a multiplicity of voices and perspectives. In cases of embedding, reported speakers may themselves bring the voices of others into the discourse. The analysis has shown that DD (586) and FDD (263) appear in a large majority of cases non-embedded. This is related to the fact that the reported element in (F)DD can be of different length and complexity sometimes a string of sentences in a single instance of direct quote. Also, since the reported element in (F)DD retains its own deictic centre, the embedding of such forms also involves a deictic switch from the host to the embedded category, increasing the complexity of the report as a whole. Moreover, if (F)DD is to serve the function of credibility and reliability, quoting the source without further mediation may be desirable.

Embedded (F)DD is much less numerous and the frequency decreases with the increase in the level of embedding: 31 instances of DD and 7 of FDD were found at level 1, whereas only 5 instances of DD were found at level 2. Also, DT ( 9 cases) appears only embedded. Apart from the complexity in form, the low frequency of embedded (F)DD also correlates with the functions the examples examined perform within their host forms. Though anecdotal, personal narratives or stretches of argumentative discourse may have their due place in newspaper reports, they are not central or essential to it.

The feeling of immediacy, personal involvement and vividness is achieved by e.g. embedded direct quotes imitating dialogic spoken discourse (examples 1, 2 and 3) or embedded direct thought (examples 10 and 11). Embedded (F)DD may function within the evaluative and comment-like component of the newspaper report. It is relied upon to communicate one's opinions and argue for one's values or desirable state of affairs (hypothetical quotes in examples 3 and 7). The ideas expressed in embedded (F)DD are either identified with (example 11) or refused and corrected (example 6). The embedded quotes can be also used for the sake of argumentation (examples 6,7 and 11). In these cases the importance of faithful reproduction may recede into the background and the only relevant factor is 
the retention of the deictic centre evocative of the reported situation and reported speaker's perspective. In other cases, form may be foregrounded, as in example 5. Embedded hypothetical (F)DD ( 9 cases) can be attributed to non-specific individuals and employed for the functions described above. Non-embedded hypothetical (F)DD (19 cases) is attributed mostly to specific elite individuals, whose presence in combination with a direct quote makes a report more valuable. Such quotes refer either to a future speech event (example 8) or less frequently to a piece of fictional discourse (example 9).

To conclude, though the structures discussed above are grammatically, deictically and semantically/pragmatically more complex, their advantage is that they bring into the discourse of newspaper reports forms and/or functions of (F)DD as well as the sources of attribution that would otherwise be much less likely to occur. Though more data are needed to ascertain the functions of the phenomena addressed, there seems to be a manifest tendency in their co-occurrence, reflecting both the nature of the phenomena and the type of text they appear in.

\section{Notes}

1 As will have been shown in the chapter dealing with hypothetical forms of representation, the term 'reported language' is to a degree unfortunate since not all instances of what is traditionally referred to as reported language are reports per se, originating in a prior speech or writing event (see e.g. Tannen 2007). Nevertheless, it will be employed here for the sake of convenience. Also, the term (free) direct reported discourse (F)DD will be used as an umbrella term covering (free) direct reported speech, writing and thought.

The $2^{\text {nd }}$ person pronoun you in example 2 could be interpreted as having generic reference (e.g. Quirk et al. 1985: 353-354).

3 See Short et al. (2002), Short et al. (1998) or Short (1988) for the use of FDD in newspaper headlines and suspension of the faithfulness claims.

4 The figure runs against Bell's (1991: 209) statement that "direct quotation is the exception not the rule in news stories". This discrepancy could be attributed either to a change in newspaper reporting and/or to the fact that Bell focuses predominantly on so-called hard news. In the present analysis, however, the distinction between hard and soft news was not made.

There is also an alternative interpretation of example 5, not endorsed in the present analysis: the instance of indirect speech (E0) representing what Emma Thompson said may not be viewed as originating with the newspaper reporter but with Mr Gove; thus the indirect speech would fall within the scope of the speech report representing what Mr Gove said (Mr Gove backed concerns from the actress Emma Thompson who said...). On this interpretation the level of embedding of the indirect speech would increase from E0 to E1 and in a likewise manner the level of embedding of all the structures within it: internal narration and the two instances of DS would appear at E2. This kind of indeterminacy is a consequence of the overall grammatical complexity of the structure, where the reporter's and reported speakers' voices mingle and the boundaries of reported forms become less clear. 


\section{References}

Bakhtin, Mikhail M. (1986) Speech Genres and Other Late Essays. Austin: University of Texas Press.

Banfield, Ann (1973) 'Narrative style and the grammar of direct and indirect speech'. Foundations of Language: International Journal of Language and Philosophy 10, 1-39.

Bell, Allan (1991) The Language of News Media. Oxford: Blackwell.

Caldas-Coulthard, Carmen R. (1994) 'On reporting reporting: the representation of speech in factual and factional narratives'. In: Coulthard, Malcolm (ed.) Advances in Written Text Analysis. London: Routledge, 295-308.

Clark, Herbert H. and Richard J. Gerrig (1990) 'Quotations as Demonstrations'. Language 66(4), 767-805.

Ehrlich, Susan (1990) Point of View: A Linguistic Analysis of Literary Style. London: Routledge.

Fludernik, Monika (1993) The Fictions of Language and the Language of Fiction. London: Routledge.

Goffman, Erving (1981) Forms of Talk. Philadelphia: University of Pennsylvania Press.

Ikeo, Reiko (2009) 'An elaboration of the faithfulness claims in direct writing'. Journal of Pragmatics 41, 999-1016.

Leech, Geoffrey N. and Michael Short (1981) Style in Fiction. London: Longman.

Quirk, Randolph, Sidney Greenbaum, Geoffrey Leech and Jan Svartvik (1985) A Comprehensive Grammar of the English Language. London: Longman.

Ryan, Marie-Laure (1991) Possible Worlds, Artificial Intelligence, and Narrative Theory. Bloomington: Indiana University Press.

Semino, Elena, Mick Short and Jonathan Culpeper (1997) 'Using a corpus to test a model of speech and thought presentation'. Poetics 25, 17-43.

Semino, Elena, Mick Short and Martin Wynne (1999) 'Hypothetical Words and Thoughts in Contemporary British Narratives'. Narrative 7(3), 307-334.

Semino Elena and Mick Short (2004) Corpus Stylistics: Speech, Writing and Thought Presentation in a Corpus of English Writing. London: Routledge.

Short, Michael (1988) 'Speech presentation, the novel and the press.' In: Van Peer, Willie (ed.) The Taming of the Text. London: Routledge, 61-81.

Short Mick, Martin Wynne and Elena Semino (1998) 'Reading Reports: Discourse Presentation in a Corpus of Narratives, with Special Reference to News Reports'. Anglistik and Englischunterricht, 39-65.

Short Mick, Elena Semino and Martin Wynne (2002) 'Revisiting the notion of faithfulness in discourse presentation using a corpus approach'. Language and Literature 11(4), 325-355.

Sternberg, Meir (1982) 'Point of View and the Indirections of Direct Speech'. Language and Style 15(1), 67-117.

Tannen, Deborah (1986) 'Introducing constructed dialogue in Greek and American Conversation and Literary Narrative'. In: Coulmas, Florian (ed.) Direct and Indirect Speech. Berlin: Mouton de Gruyter, 311-331.

Tannen, Deborah (2007) Talking Voices: Repetition, Dialogue, and Imaginary in Conversational Discourse. $2^{\text {nd }}$ ed. Cambridge: Cambridge University Press.

Vandelanotte, Lieven (2009) Speech and Thought Representation in English. Berlin: Walter de Gruyter.

van Dijk, Teun A. (1988) News as Discourse. Hillsdale: Lawrence Erlbaum Associates.

Waugh, Linda R. (1995) 'Reported speech in journalistic discourse'. Text 15, 129-173. 


\section{Sources}

'Blair brought military close to seizing up, says ex-army chief'. The Guardian, 29 July 2010.

'Cameron: I didn't think I would become a Prime Minister'. The Independent, 29 July 2010.

'Cameron: we must back doers and grafters who will get economy moving'. The Daily Telegraph, October 6, 2010.

'Channel 4 defends its kidnap drama fiction about Prince Harry'. The Guardian, October 7, 2010.

'Child benefit: I should have warned you, admits MP'. The Daily Telegraph, October 6, 2010.

'Cuts won't be easy but there is no alternative, says PM'. The Guardian, October 7, 2010.

'Man joked about parasail before falling to his death'. The Independent, 29 July 2010.

'No dramas, but assured speech steadies party'. The Independent, October 7, 2010.

'Pupils will learn our island story, promises Schama'. The Daily Telegraph, October 6, 2010.

'R.E.S.P.E.C.T. Find out what it means to Condi'. The Independent, 29 July 2010.

'You'll never worry alone: fans in nervous wait to learn who will own Liverpool FC'. The Guardian, 29 July 2010.

Zuzana Urbanová teaches at the University of Pardubice. Her main research interests and publications concern the areas of reported language (Faithfulness/Verbatim Reproduction in Direct Reported Forms: An Overview), the discourse of newspaper reports (Newspaper reports: lexis, discourse pattern and coherence), cohesion and coherence, especially Rhetorical Structure Theory (The Function of Reported Language in the Discourse of Newspaper Reports). She has been working on her Ph.D. since 2007 and currently she focuses mainly on direct forms of representation and their function in the generic structure of newspaper reports.

Address: Mgr. Zuzana Urbanová, Department of English and American Studies, Faculty of Arts, University of Pardubice, Studentská 84, Pardubice 532 10, Czech Republic. [e-mail: zuzana.urbanova@upce.cz] 